\title{
Morphological priming without semantic relationship in Hebrew spoken word recognition
}

\author{
Jonathan Geary \& Adam Ussishkin*
}

\begin{abstract}
We report on an auditory masked priming study designed to test the contributions of semantics and morphology to spoken word recognition in Hebrew. Thirty-one native Hebrew speakers judged the lexicality of Hebrew words that were primed by words which either share their root morpheme and a transparent semantic relationship with the target (e.g. porets פריצה פטורץ 'burglar' priming pritsa') or share their root morpheme but lack a transparent semantic relationship with the target (e.g. mifrats מפרץ 'gulf' priming pritsa פריצה 'burglary'). We found facilitatory priming by both types of morphological relatives, supporting that semantic overlap is not required for morphological priming in Hebrew spoken word recognition. Thus, our results extend the findings of Frost, Forster, \& Deutsch's (1997) Experiment 5 to the auditory modality, while avoiding confounds between root priming and Hebrew's abjad orthography associated with the visual masked priming paradigm. Further, our results are inconsistent with models of word processing which treat morphological priming as reflecting form and semantic coactivation, and instead support an independent role for root morphology in Hebrew lexical processing.
\end{abstract}

Keywords. Semitic; morphological processing; semantics; auditory masked priming

1. Introduction. Morphology is often described as being at the intersection of phonology and semantics, in that morphemes (typically) represent a unique combination of form and meaning that remains stable across words (e.g. Hockett 1958: 123). Yet an ongoing question concerns the role of morphology as separate from that of form and meaning in lexical processing. Models of word recognition can be divided into two main types according to the role which they ascribe to morphology in lexical processing: Decomposition-based models assume that, during processing, language users decompose complex words into their constituent morphemes, which then activate the lexical representations of those morphemes, leading to the word's successful recognition by way of these morphemic units (e.g. Frost et al. 1997, Rastle et al. 2004). For instance, when an English listener hears the word cleaner, they decompose the word into clean and -er, activating the lexical representations associated with these morphemes. Holistic models, on the other hand, assume no decomposition stage in lexical processing. Rather, words are recognized holistically, and any apparent effects of morphology may simply reflect the combined effects of phonological and semantic coactivation (e.g. Baayen et al. 2011; Milin et al. 2017) (see also Milin et al. (2018) for a review of morphological processing in models of word recognition).

The results of early priming work supported that morphology mediates lexical processing independent of semantics. For instance, Emmorey (1989) found that English listeners were faster to judge the lexicality of real words when primed supraliminally by morphological relatives with which the target lacks a semantic relationship (e.g. submit priming permit). Emmorey interpreted this result as suggesting that listeners may maintain morphological relationships lexically even in

\footnotetext{
* The authors wish to thank Skye Anderson, Netta Ben-Meir, Evan Gary Cohen, Stephen Cowen, Kenneth I. Forster, Roey Gafter, Lior Laks, Kevin Schluter, and Hadas Velan for their support and expertise; the native Hebrew speaker who recorded the items for this study; and the Tel Aviv University Department of Linguistics for their assistance in recruiting participants. All remaining mistakes are the responsibility of the authors.

Authors: Jonathan Geary, University of Arizona (jonathangeary@email.arizona.edu) \& Adam Ussishkin, University of Arizona (ussishki@email.arizona.edu). 
the absence of a semantic relationship between words. In a visual masked priming study, Rastle et al. (2004) similarly found that English readers were faster to judge target lexicality following a prime that is unrelated to the target semantically, but which exhibits an apparent morphological relationship with the target based on orthographic form (e.g. corner, which looks decomposable into corn + -er, priming CORN) (see also Forster \& Azuma (2000) for similar findings), which they interpreted as suggesting that readers decompose words based on their morpho-orthographic form without consideration of semantics (cf. brothel does not prime BROTH, as brothel does not appear decomposable into broth + -el since English lacks an -el suffix) (Rastle \& Davis 2008).

More recent research, however, has suggested that semantics mediates morphological processing. For instance, using visual masked priming with both lexical and semantic decision, Jared et al. (2017) found graded effects of semantic transparency between the prime and target: priming effects were greater for prime-target pairs exhibiting a transparent semantic relationship (e.g. foolish priming FOOL) than for those sharing a quasi-transparent relationship (e.g. bookish priming $B O O K$ ), while priming effects were even smaller for pairs having an opaque relationship (e.g. vanish priming $V A N$ ). The results are consistent with both decomposition-based and holistic models of word recognition, yet they suggest that whether decomposition occurs depends on the word's semantics and not simply on its morpho-orthographic form (cf. Rastle \& Davis 2008).

Semitic languages provide unique testing conditions for the role of morphology in lexical processing because of the discontinuous nature of their morphology. In Semitic languages, native word stems usually consist of two discontinuous morphemes (Berman 1978): a consonantal root, which provides the word's core meaning (e.g. $l-\check{s}-n$ ל-ש- 'SPEAKING' in malšin מלשין 'informer'); and a vocalic and consonantal pattern, which contributes grammatical and thematic information (e.g. maktil מקטיל, wherein the letters $k-t-l$ ק־ט-ט indicate the positions of the root consonants, in malšin מלשין 'informer'). These morphemes may recur in other words, and words which share a

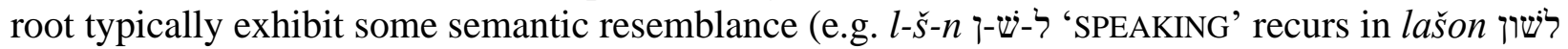
'tongue, language', halšana הלשנה 'informing', and balšanut בלשנות 'linguistics').

The role of root and pattern morphology in word processing has been probed using various experimental methodologies, including priming. For instance, under masked priming conditions, Hebrew readers have consistently been found to provide faster lexicality judgements for Hebrew words when primed by another word sharing the target's root (e.g. porets פורץ 'burglar' priming pritsa פריצה 'burglary'), but not necessarily when primed by another word sharing its pattern (e.g. targil תרגיל 'record') (Deutsch et al. 1998; Frost et al. 1997, 2000, 2005). Comparable priming by root-derivatives has also been observed in the visual modality in Arabic (Boudelaa \& Marslen-Wilson 2001, 2004) and Maltese (Twist 2006), and nonce strings corresponding to the word's root likewise prime in Maltese (e.g. frx priming FIREX 'to spread') (Geary \& Ussishkin 2018). Priming by root-related words has also been obtained in the auditory modality in Moroccan Arabic (Schluter 2013) and Maltese (Ussishkin et al. 2015).

Although most words sharing a root also share some core meaning, some morphological relatives lack a transparent semantic relationship due to semantic drift (cf. pritsa פפריצה 'burglary'

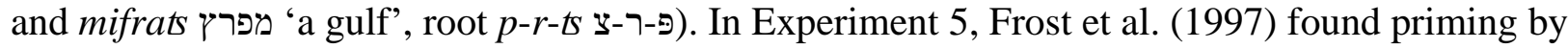
such root-related items, which they interpreted as suggesting that, not only are root morphemes lexically represented and involved in word processing, but morphological relationships can exist in the lexicon even in the absence of semantic relatedness. However, a potential confound exists in that (a) Semitic roots are entirely consonantal and (b) Hebrew's abjad orthography, in which only consonants and some vowels are written, privileges consonant letters, and so any apparent root priming effect in Hebrew visual word recognition may simply reflect an orthographic bias 
rather than a true effect of morphological priming (further, this may explain the lack of priming by words which share a pattern, as many of the pattern's letters are omitted in written form). To circumvent this, we can look for root priming effects in the auditory modality, where consonants and vowels are both represented. Thus, in the present study we aim to replicate Experiment 5 of Frost et al. (1997) in the auditory modality, using an auditory analog of visual masked priming.

\section{Methods.}

2.1 PARTICIPANTS. Thirty-one native Hebrew speakers participated in the study. All participants were recruited either from the Department of Linguistics at Tel Aviv University (TAU) or from Amazon Mechanical Turk's (MTurk) worker pool (all workers were required to be located in Israel to participate). TAU participants received credit towards their degree in return for their participation, while MTurk participants received \$2.00. The average age of participants was 24.3 years (range: 19-37 years). Fourteen participants identified as female and 17 as male. Twentynine participants identified as right-handed and 2 as left-handed. Three additional participants completed the study but reported awareness of the primes, and so we do not analyze their results.

2.2 MATERIALS. Participants identified the lexicality of 120 auditorily-presented targets: 60 real Hebrew words and 60 non-words. ${ }^{1}$ Each real-word target was paired with four primes (Table 1):

1. a "repetition" prime, which is identical to the target;

2. a "M+S+" prime, which is morphologically related to the target in that they share their root morpheme, and which exhibits a transparent semantic relationship to the target;

3. a "M+S-" prime, which is morphologically related to the target in that they share their root morpheme, but which lacks a transparent semantic relationship to the target;

4. an "unrelated" prime, which lacks morphological and semantic relationship to the target (the root morpheme of this prime shares at least one segment with that of the target).

\begin{tabular}{|c|c|c|c|c|c|c|}
\hline Priming condition & \multicolumn{3}{|c|}{ Prime } & \multicolumn{3}{|c|}{ Target } \\
\hline Repetition & pritsa & פּריצה & 'burglary' & pritsa & פריצה & 'burglary' \\
\hline $\mathrm{M}+\mathrm{S}+$ & porets & פּורץ & 'a burglar' & pritsa & פּריצה & 'burglary' \\
\hline $\mathrm{M}+\mathrm{S}-$ & mifrats & מפרץ & 'a gulf' & pritsa & פּריצה & 'burglary' \\
\hline Unrelated & Paritsut & עריצות & 'tyranny' & pritsa & פּריצה & 'burglary' \\
\hline
\end{tabular}

Table 1: Example prime-target pairs for which the target is a real word. In these pairs, the target and repetition, $\mathrm{M}+\mathrm{S}+$, and $\mathrm{M}+\mathrm{S}-$ primes share the root $p-r-t s$ צ-ר- $:$, while the unrelated prime contains the root $P-r-t 5$ צ-ר.

All real-word targets and primes comprised nouns, and all root morphemes were triliteral. The plosives /p, $\mathrm{k}, \mathrm{b}$ / spirantize in certain contexts in Modern Hebrew, becoming [f, x, v] (Bolozky 1997: 287-288), and so the surface realization of the roots of some $\mathrm{M}+\mathrm{S}+$ and $\mathrm{M}+\mathrm{S}-$ primes differ from that of their associated target in that they exhibit a plosive-fricative alternation.

Real-word items were identical to those used in Experiment 5 of Frost et al. (1997), with the following exceptions: First, three of the unrelated primes recurred elsewhere in their study (mavrik מכתב משר 'a letter', and mišpat משרפט 'a trial') and so were replaced (with mivrešet מברשת 'a brush', maxar מחר 'משר 'tomorrow', and miškal משקל 'weight', respectively). Second, nine unrelated primes had roots which recur in other items in the experiment (hatxala התחלה 'beginning', root: $t$-x-l; magleša מגלשה 'a slide', root: g-l-š; matpera מתפרה 'a sewing

\footnotetext{
${ }^{1}$ The full list of items is available at: http://u.arizona.edu/ jonathangeary/Materials/LSA2019/ItemList.pdf.
} 
workshop', root: $t-p-r$; šlavim שלבים 'stages', root: $\check{s}-l-b$; toxelet תוחלת 'hope', root: $t$ - $x$-l; šiluv

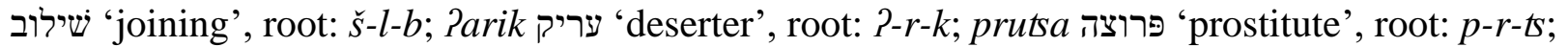
and šikuf שיקוב 'a reflection', root: $\left.\check{s}^{-} k-p\right)$. ${ }^{2}$ To avoid confounding effects of morpheme repetition, these items too were replaced (with hatslaxa הצלחה 'success', root: ts-l-x; magrefa מגרפה 'a rake',

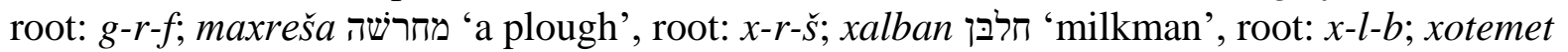
חותמת 'a stamp', root: $x$-t-m; šalaf שלף 'pulled out; stubble', root:

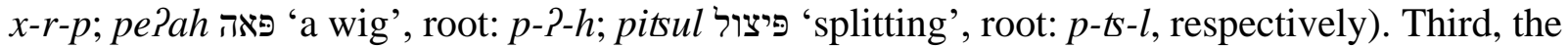
unrelated prime šavu?ot שבועות 'Pentecost' was replaced with mixšol מכשול 'an obstacle'.

For each real-word target, a non-word target was created by replacing the root morpheme with a phonotactically legal but unattested root (cf. Ussishkin et al. (2015), who used a similar method). Non-word construction respected Hebrew phonotactic restrictions, and we avoided non-words which participants could interpret as having an existing root because of either the spirantization or voicing assimilation of one of the root consonants (Bolozky 1997). Each nonword target was paired with one prime: a real-word that is unrelated to any other item used in the experiment, and the root of which shares at most two consonants with that of the target (Table 2).

\begin{tabular}{lccc}
\multicolumn{3}{c}{ Prime } \\
\hline mavhil & Target \\
\hline
\end{tabular}

Table 2: Example prime-target pair for which the הלנבה target is a non-word. The nonce target halnava was created by replacing the root of the real-word target hadraxa הדרכה 'guidance' (root: $d-r-x$ ד־ר־) with the unattested root $l-n-b$ ב-נ-ל.

Another ten items were used as practice targets: five real-word targets and five non-word targets. Each practice target was paired with a single prime: an unrelated, real word.

All items were vetted by two native Hebrew speakers, who removed any non-word targets judged to be interpretable as a real word (e.g. as a real word which bears a prefix), to sound too similar to a real word, or to otherwise sound unlike a Hebrew word. Additionally, during the recording session (Section 2.3) the speaker was instructed to pronounce the non-word targets "as naturally as possible", being granted the liberty to make small changes to the quality of vowels, to spirantize the plosives /p, k, b/, and to voice/devoice obstruents where appropriate.

During the experiment, targets were presented embedded in "noise". This noise included the prime and a series of forward and backward masks. Like the primes, all masks comprised real words. Since the masks were manipulated such that they would be unrecognizable to participants (Section 2.4), no restrictions were placed on which words could be used as masks.

Four lists counterbalanced by priming condition for the real-word targets were constructed using a Latin square design: each real-word prime-target pair occurred in one and only one list (with each list containing an equal number of each type of prime), and each non-word primetarget pair occurred in each list. Participants were assigned randomly to one and only one list.

2.3 RECORDING. Items were recorded by a female, native speaker of Hebrew. All recordings were made in the Douglass Phonetics Lab at the University of Arizona. The speaker sat in a soundattenuated booth while wearing a high-quality, head-mounted microphone and was instructed to

\footnotetext{
${ }^{2}$ For several such primes, this was not an issue in the original Frost et al. (1997) experiment because these roots are distinguished orthographically. However, the phonetic realizations of certain letters have merged in Modern Hebrew (e.g. ת/t/ and $\bullet / t /$ (historical value: / $/ \theta /)$ ), resulting in root morphemes which are homophonous.
} 
read each item aloud from a printed list in a relaxed yet careful manner. Recordings were made using an Alesis ML9600 Masterlink CD recorder, which recorded at a sampling rate of 44,100 $\mathrm{Hz}$. The speaker was free to practice the non-words and any unfamiliar or difficult real-word items, but she pronounced each item at least three times. The "best" token of the three (i.e. that with the clearest enunciation, the most neutral intonation, and no non-linguistic intrusions such as coughs) was selected for use in the experiment. Mean duration across targets was $760 \mathrm{~ms}$; for real words, mean duration was $747 \mathrm{~ms}$, while for non-words, mean duration was $773 \mathrm{~ms}$.

2.4 STIMULUS CONSTRUCTION. Prime-target pairs were presented using the auditory masked priming paradigm first developed by Kouider \& Dupoux (2005): on each trial, participants first heard the forward mask, then the prime, and then the target and a series of backward masks which overlapped temporally with the target (Figure 1 illustrates the structure of a typical trial). The primes were masked by being durationally compressed and amplitude-attenuated $(-15 \mathrm{~dB})$, as well as by being embedded in the series of forward and backward masks. The forward and backward masks were similarly compressed and amplitude-attenuated, as well as temporally reversed in order to prevent their identification as words. Five backward masks were used to ensure that the offset of the target always occurred before the offset of the final backward mask.

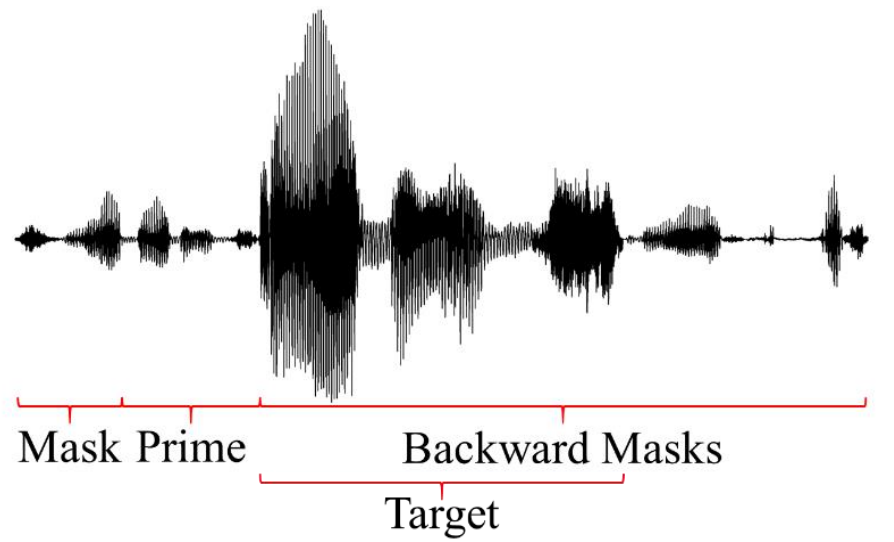

Figure 1. Structure of a trial.

Although Kouider \& Dupoux (2005) compressed their primes and masks using a fixed compression rate of $35 \%$ of their original duration, we compressed the primes and masks in this experiment to a fixed duration of $240 \mathrm{~ms}$ (following Schluter (2013)), as participants in a pilot study exhibited conscious awareness of the primes when a $35 \%$ compression rate was used. ${ }^{3} \mathrm{We}$ compressed the primes and masks using the $\mathrm{P}$ (itch) $\mathrm{S}$ (ynchronous) $\mathrm{O}$ (ver)L(ap) A(dd) algorithm, which compresses the items while keeping their pitch constant. The prime, target, and masks for each trial were concatenated into a single .wav file which was played during the experiment.

2.5 PROCEDURES. All procedures took place on participants' computers. In order to participate in the experiment, participants first downloaded a .exe file containing: the experimental software, DMDX (Forster \& Forster 2003); the item files necessary to run the experiment (e.g. the .rtf file containing the instructions for stimulus presentation for DMDX and the audio files); and a poster and batch file which, upon the completion of the experiment, sent the results to the first author's

\footnotetext{
${ }^{3}$ This may reflect the fact that some of the primes in this experiment were quite long prior to compression (e.g. $1 \mathrm{~s}$ or longer), and so they remained long enough to be consciously processed when a fixed compression rate was used.
} 
email address and to a secure, password-protected server at the University of Arizona. ${ }^{4}$ Opening the file launched DMDX and began the experiment. The experimental software did not actually install on participants' computers; rather, it simply ran, uploaded the results of the experiment, and then was deleted. Participants were instructed to complete the experiment in a quiet room, but otherwise were free to choose when and where to complete the experiment.

Upon starting the experiment, participants were presented on-screen with the disclosure form and, after reading it, were asked to press a button to indicate their consent to participate. Participants were instructed that they needed to wear headphones during the experiment and, after the consent procedures, DMDX ran a sound test which allowed them to set the volume on their computer to an audible yet comfortable level before beginning the experiment proper.

Participants were then instructed that, on each trial of the experiment, they would hear something intelligible (i.e. the target), which may or may not be a real word of Hebrew, which would be embedded in "noise" (i.e. the prime and masks; participants typically judge this to sound "like an alien language" or "like background chatter at a party"). They were instructed to perform a lexical decision on the intelligible portion of each trial by pressing the right arrow key if what they heard was a word and the left arrow key otherwise. If no response was given within $3000 \mathrm{~ms}$ of stimulus onset, DMDX recorded it as a non-response and moved on to the next trial. Other than reference to the "noise" in the instructions, no mention was made of the existence of the primes. After reading the instructions, participants completed the ten practice trials, during which they received feedback for correct, incorrect, and null responses. After completing the practice block, participants completed the 120 trials of the experiment proper. The experiment trials were randomized such that participants could receive no more than four real-word targets or four non-word targets in a row. Participants responded on each trial in the same manner as in the practice block, though during the experiment proper they received no feedback for correct and incorrect responses. Participants took a break after the $60^{\text {th }}$ trial.

After completing the experimental task, participants were asked on-screen to complete a short background questionnaire which included questions about their age, gender, handedness, language background, and whether they had ever been diagnosed with a hearing problem by a doctor. Additionally, participants were asked whether they wore headphones during the study; this allowed data from participants who did not properly complete the experiment to be excluded from the analysis. After completing the questionnaire, they were debriefed on-screen and then DMDX closed. Their results were then sent to the first author's email address and uploaded to a secure, password-protected server at the University of Arizona in the form of a azk file.

\section{Results.}

\begin{tabular}{lcccc} 
Priming condition & Mean & SEM & Net priming & Accuracy rate \\
\hline Repetition & 1,058 & 14.0 & 37 & $95.7 \%$ \\
M+S+ & 1,065 & 13.9 & 30 & $95.1 \%$ \\
M+S- & 1,066 & 13.8 & 29 & $92.7 \%$ \\
Unrelated & 1,095 & 14.2 & ----- & $95.5 \%$ \\
OVERALL & 1,071 & 7.0 & ----- & $94.7 \%$ \\
\hline
\end{tabular}

Table 3: Mean RT (ms) and accuracy rate for real-word targets.

\footnotetext{
${ }^{4}$ Additionally, the experiment was programed to email a diagnostics report to the author if DMDX aborted the experiment prematurely, and any errors encountered by DMDX during the experiment were recorded in the results file, allowing data from participants for whom the experiment did not run properly to be excluded from analysis.
} 
3.1 DATA ANALYSIS. Mean RTs and accuracy rates for real-word trials are presented in Table 3. RT to real-word targets on trials in which participant gave the correct response $(94.7 \%$ of realword trials) was analyzed using a linear mixed-effects regression (LMER) analysis, using the lme4 package (Bates et al. 2015) to fit a LMER model in R (R Core Team 2017). We analyzed negative reciprocal RT (i.e. $-1000 /$ RT) from target onset: we used a reciprocal transformation to compensate for the effects of positive skew which are typical of masked priming studies, and we analyzed negative reciprocal RT to preserve the relative direction of effects (Kliegl et al. 2010). We assessed the significance of model parameters by using the lmerTest package (Kuznetsova et al. 2016) to compute $p$-values using Satterthwaite approximations for degrees of freedom.

The fitted model for the RT analysis included negative reciprocal RT as the dependent variable; participants and targets as random effects; and priming condition (levels: Unrelated, Repetition, $\mathrm{M}+\mathrm{S}+$, and $\mathrm{M}+\mathrm{S}-$; with Unrelated set as the reference level), log-transformed target frequency (Frost \& Plaut 2005), and log-transformed target duration as fixed effects. We removed outliers by fitting one model to the full dataset and then applying a model-based trimming procedure which, given a linear model, trims from the fitted dataset datapoints for which the residual standard score is more than 2.5 units from the mean of zero. This removed 37 datapoints (2.1\% of the dataset). Then we fit a new LMER model to the trimmed dataset.

We also fitted models which included random slopes for priming condition by-participants and by-targets. However, the results of a series of likelihood ratio tests comparing these models with the random intercepts model suggest that random slops for priming condition are justified neither by-participants $\left(\chi^{2}(9)=5.57, p>0.05\right)$ nor by-targets for this dataset $\left(\chi^{2}(9)=2.46, p>\right.$ $0.05)$, and so we report the results of the random intercepts model below.

Accuracy of responses to real-word targets was analyzed using a generalized linear mixedeffects regression (GLMER) analysis, using the lme4 package (Bates et al. 2015) to fit a GLMER model in $\mathrm{R}$ ( $\mathrm{R}$ Core Team 2017). The fitted model included response accuracy $(0=$ Incorrect, $1=$ Correct) as the dependent variable; participants and targets as random effects; and priming condition (levels: Unrelated, Repetition, $\mathrm{M}+\mathrm{S}+$, and $\mathrm{M}+\mathrm{S}-$; with Unrelated set as the reference level) and log-transformed target frequency as fixed effects (a model including target duration failed to converge). Models with random slopes for priming condition by-participants and bytargets failed to converge, and so we report the results of the random intercepts model below.

3.2 RT ANALYSIS. The results of the analysis of RTs to real-word targets revealed significant effects of $\log$ target frequency $(\beta=-0.013, t(57.3)=-2.07, p<0.05)$ and of log target duration $(\beta=0.349, t(57.1)=6.11, p<0.001)$. All else being equal, participants were faster to respond as target frequency increased, and slower to respond as target duration increased.

Moreover, the analysis revealed significant effects at the Repetition $(\beta=-0.043, t(1,645)=$ $-4.86, p<0.001), \mathrm{M}+\mathrm{S}+(\beta=-0.027, t(1,654)=-3.08, p<0.005)$, and $\mathrm{M}+\mathrm{S}-$ levels of priming condition $(\beta=-0.023, t(1,644)=-2.54, p<0.05)$. All else being equal, participants were faster to respond in the Repetition, $\mathrm{M}+\mathrm{S}+$, and $\mathrm{M}+\mathrm{S}-$ conditions than in the Unrelated condition. That is, regardless of whether they share a transparent semantic relationship, primes which share the target's root morpheme facilitate target recognition. These results are summarized in Figure 2.

3.3 RESPONSE ACCURACY ANALYSIS. The results of the analysis of response accuracy to realword targets revealed a significant effect of log target frequency $(\beta=0.382, z=3.25, p<0.005)$. All else being equal, participants responded more accurately as target frequency increased. In contrast, the effects of priming condition at the Repetition $(\beta=0.067, z=0.20, p>0.05), \mathrm{M}+\mathrm{S}+$ $(\beta=-0.044, z=-0.14, p>0.05)$, and $\mathrm{M}+\mathrm{S}-$ levels $(\beta=-0.518, z=-1.71, p>0.05)$ failed to 
reach significance. That is, the accuracy of participants' responses did not reliably differ between the Repetition, $\mathrm{M}+\mathrm{S}+$, or $\mathrm{M}+\mathrm{S}-$ condition and the Unrelated condition.

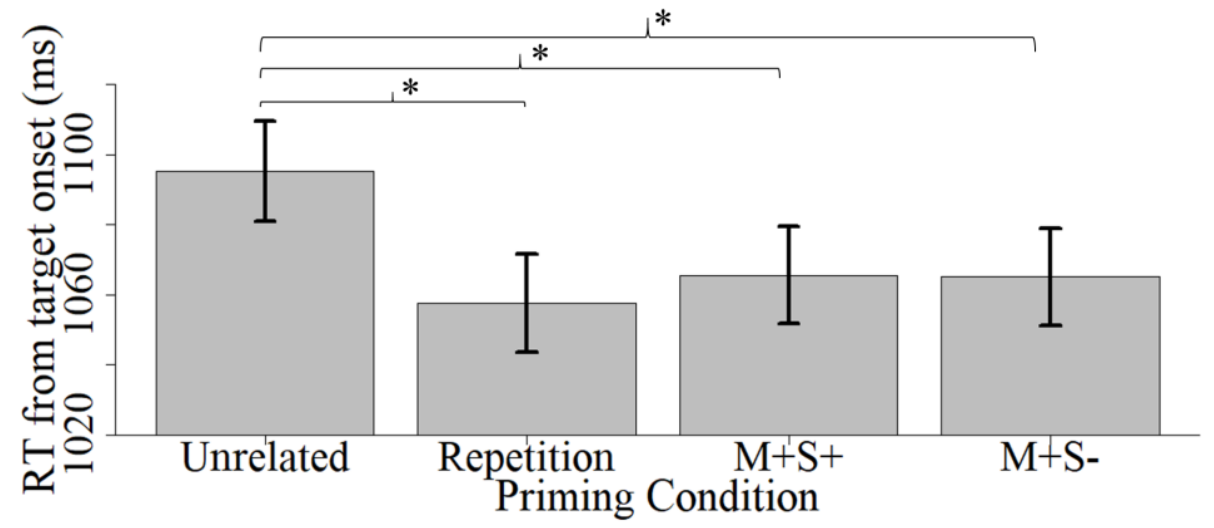

Figure 2. Mean RT (ms) as a function of priming condition. Error bars denote standard error. Asterisks denote that a difference between conditions is statistically significant.

4. Discussion. In an auditory masked priming experiment, we found that Hebrew listeners were faster to judge the lexicality of Hebrew words when primed by another word sharing the target's root morpheme. This facilitation effect held regardless of whether the prime and the target shared

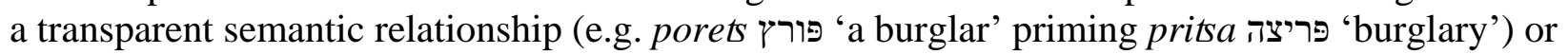
not (e.g. mifrats פפרץ 'a gulf' priming pritsa פריצה 'burglary'). Thus, our results extend those of Frost et al.'s (1997) Experiment 5 to the auditory modality, while avoiding potential confounds between root morphology and Hebrew's abjad orthography which are inherent in the use of the visual masked priming paradigm. That is, in both the visual and auditory modalities, Hebrew words prime when they share a root morpheme, independent of semantics.

The results of the present study are consistent with a role for root morphology in Hebrew spoken word recognition. One possibility is an activation-based model in which root morphemes are represented lexically at a level separate from semantics. When Hebrew listeners hear a word, they decompose it into its constituent morphemes, including root and pattern, thus activating this representation of the root. Activation then spreads from the root to other words which share this morpheme, facilitating their subsequent recognition and giving rise to the priming effects found in the present study. Our results are inconsistent with learning-based models of word processing, such as the Naive Discriminative Learning model (Baayen et al. 2011), which hold that apparent morphological priming effects reflect the coactivation of form and meaning, as the observed priming effects arise in the absence of semantic overlap and thus meaning-based activation.

In the present study, we have disentangled morphological processing from semantics, but we have not shown that morphological priming is distinct from form-based priming; that is, that morphological processing is distinct from phonology. Forster \& Azuma (2000), using the visual masked priming paradigm, disentangled morphology from form by showing that form priming effects (e.g. shallow priming FOLLOW) disappear under priming conditions (namely, the use of longer prime durations) in which morphological priming persists. Returning to Hebrew, Frost et al. (2005: Experiment 4) obtained facilitatory priming by root-related primes (e.g. harkada הרקדה 'lead to dance' priming rikud ריקוד 'dance', root $r$ - $k$ - $d$ ר-ק-ק wile failing to obtain priming by primes which lack a morphological relationship yet overlap in a greater proportion of letters with the target (e.g. ripud ריפוד 'upholstery' priming rikud 'dance'), and we propose an auditory replication of this experiment as a means of disentangling morphology from phonological form. 


\section{References}

Baayen, R. Harald, Petar Milin, Dusica Filipović Đurđević, Peter Hendrix, \& Marco Marelli. 2011. An amorphous model for morphological processing in visual comprehension based on naive discriminative learning. Psychological Review 118. 438-481. https://doi.org/10.1037/a0023851.

Bates, Douglas, Martin Mächler, Benjamin M. Bolker, \& Steven C. Walker. 2015. Fitting linear mixed-effects models using lme4. Journal of Statistical Software 67. 1-48. https://doi.org/10.18637/jss.v067.i01.

Berman, Ruth A. 1978. Modern Hebrew structure. Tel-Aviv: University Publishing Projects. Bolozky, Shmuel. 1997. Israeli Hebrew Phonology. In Alan S. Kaye (ed.), Phonologies of Asia and Africa. 287-311. Indiana: Eisenbrauns.

Boudelaa, Sami, \& William D. Marslen-Wilson. 2001. The time-course of morphological, phonological, and semantic processes in reading Modern Standard Arabic. Proceedings of the Annual Meeting of the Cognitive Science Society 23. 138-143. Edinburgh, Scotland. https://escholarship.org/uc/item/33n880t7.

Boudelaa, Sami, \& William D. Marslen-Wilson. 2004. Allomorphic variation in Arabic: implications for lexical processing and representation. Brain and Language 90. 106-116. https://doi.org/10.1016/S0093-934X(03)00424-3.

Deutsch, Avital, Ram Frost, \& Kenneth I. Forster. 1998. Verbs and nouns are organized and accessed differently in the mental lexicon: evidence from Hebrew. Journal of Experimental Psychology: Learning, Memory, and Cognition 24. 1238-1255. https://doi.org/10.1037/0278-7393.24.5.1238.

Emmorey, Karen D. 1989. Auditory morphological priming in the lexicon. Language and Cognitive Processes 4. 73-92. https://doi.org/10.1080/01690968908406358.

Forster, Kenneth I., \& Tamiko Azuma. 2000. Masked priming for prefixed words with bound stems: does submit prime permit? Language and Cognitive Processes 15. 539-561. https://doi.org/10.1080/01690960050119698.

Forster, Kenneth I., \& Jonathan C. Forster. 2003. DMDX: a Windows display program with millisecond accuracy. Behavior Research Methods, Instruments, \& Computers 35. 116124. https://doi.org/10.3758/BF03195503.

Frost, Ram, Avital Deutsch, \& Kenneth I. Forster. 2000. Decomposing morphologically complex words in a nonlinear morphology. Journal of Experimental Psychology: Learning, Memory, and Cognition 26. 751-765. https://doi.org/10.1037/0278-7393.26.3.751.

Frost, Ram, Kenneth I. Forster, \& Avital Deutsch. 1997. What can we learn from the morphology of Hebrew? A masked-priming investigation of morphological representation. Journal of Experimental Psychology: Learning, Memory, and Cognition 23. 829-856. https://doi.org/10.1037/0278-7393.23.4.829.

Frost, Ram, Tamar Kugler, Avital Deutsch, \& Kenneth I. Forster. 2005. Orthographic structure versus morphological structure: principles of lexical organization in a given language. Journal of Experimental Psychology: Learning, Memory, and Cognition 31. 1293-1326. https://doi.org/10.1037/0278-7393.31.6.1293.

Frost, Ram, \& Dave Plaut. 2005. The word-frequency database for printed Hebrew. Available at http://word-freq.mscc.huji.ac.il/.

Geary, Jonathan A., \& Adam Ussishkin. 2018. Root-letter priming in Maltese visual word recognition. The Mental Lexicon 13. 1-25. https://doi.org/10.1075/ml.18001.gea.

Hockett, Charles F. 1958. A course in modern linguistics. New York: The Macmillan Company. 
Jared, Debra, Olessia Jouravlev, \& Marc F. Joanisse. 2017. The effect of semantic transparency on the processing of morphologically derived words: evidence from decision latencies and event-related potentials. Journal of Experimental Psychology: Learning, Memory, and Cognition 43. 422-450. https://doi.org/10.1037/xlm0000316.

Kliegl, Reinhold, Michael E. J. Masson, \& Eike M. Richter. 2010. A linear mixed model analysis of masked repetition priming. Visual Cognition 18. 655-681. https://doi.org/10.1080/13506280902986058.

Kouider, Sid, \& Emmanuel Dupoux. 2005. Subliminal speech priming. Psychological Science 16: 617-625. https://doi.org/10.1111/j.1467-9280.2005.01584.x.

Kuznetsova, Alexandra, Per Brun Brockhoff, \& Rune Haubo Bojesen Christensen. 2016. lmerTest: Tests in linear mixed effects models. [R package v. 2.0-32]. https://CRAN.Rproject.org/package=lmerTest.

Milin, Petar, Laurie Beth Feldman, Michael Ramscar, Peter Hendrix, \& R. Harald Baayen. 2017. Discrimination in lexical decision. PLoS One 12. https://doi.org/10.1371/ journal.pone.0171935.

Milin, Petar, Eva Smolka, \& Laurie Beth Feldman. 2018. Models of lexical access and morphological processing. In Eva M. Fernández \& Helen Smith Cairns (eds.), The Handbook of psycholinguistics. 240-268. Hoboken, NJ: Wiley-Blackwell. http://doi.org/10.1002/9781118829516.ch11.

R Core Team. 2017. R: A language and environment for statistical computing. R Foundation for Statistical Computing, Vienna, Austria. https://www.R-project.org/.

Rastle, Kathleen, \& Matthew H. Davis. 2008. Morphological decomposition based on the analysis of orthography. Language and Cognitive Processes 23. 942-971. https://doi.org/10.1080/01690960802069730.

Rastle, Kathleen, Matthew H. Davis, \& Boris New. 2004. The broth in my brother's brothel: morpho-orthographic segmentation in visual word recognition. Psychonomic Bulletin \& Review 11. 1090-1098. http://doi.org/10.3758/BF03196742.

Schluter, Kevin T. 2013. Hearing words without structure: subliminal speech priming and the organization of the Moroccan Arabic lexicon. PhD dissertation, University of Arizona. http://hdl.handle.net/10150/301752.

Twist, Alina E. 2006. A psycholinguistic investigation of the verbal morphology of Maltese. $\mathrm{PhD}$ dissertation, University of Arizona. http://hdl.handle.net/10150/194996.

Ussishkin, Adam, Colin Reimer Dawson, Andrew Wedel, \& Kevin Schluter. 2015. Auditory masked priming in Maltese spoken word recognition. Language, Cognition, and Neuroscience 30. 1096-1115. https://doi.org/10.1080/23273798.2015.1005635. 